\section{Squamous cell carcinoma in a retrorectal cystic hamartoma}

\author{
Ana Teijo Quintáns ${ }^{1 *}$, José Ignacio Martín Valadés ${ }^{2}$, Cristina \\ Garrán del Río ${ }^{3}$, Irene López Rojo ${ }^{4}$ and Oscar Alonso Casado ${ }^{4}$ \\ 'Pathology Department, Hospital 12 de Octubre, MD Anderson Cancer Center, Madrid, Spain \\ 2Oncology Department, MD Anderson Cancer Center Madrid, Spain \\ ${ }^{3}$ Oncology Radiotherapy Department, MD Anderson Cancer Center Madrid, Spain \\ ${ }^{4}$ Surgery Department, MD Anderson Cancer Center Madrid, Spain
}

\section{Abstract}

Retrorectal cystic hamartomas (HCR) ("tailgut cyst" in English-language literature) are congenital cystic tumors derived from vestiges of the hindgut. Its incidence is low, being more frequent in adult women. They are variable in size, uni or multiloculated. They can be lined with several types of epithelia (squamous, transitional, mucinous,...) in a same cyst and can contain mucus. Lesions usually present during adulthood due to pain, discomfort, rectal bleeding, infection, or malignant transformation. The incidence of malignancy is low, being adenocarcinoma and neuroendocrine the most frequent tumors associated to HCR. We present a case of HCR associated with squamous cell carcinoma and discuss aspects of the treatment.
More Information

*Address for Correspondence: Ana Teijo Quintáns, Pathology department Hospital 12 de Octubre/MD Anderson Cancer Center, C/ Arturo Soria 270 cp: 28033, Madrid, Spain, Email: ateijo4@gmail.com

Submitted: December 29, 2021 Approved: January 19, 2022 Published: January 20, 2022

How to cite this article: Quintáns AT, Valadés JIM, del Río CG, Rojo IL, Casado OA. Squamous cell carcinoma in a retrorectal cystic hamartoma. J Radiol Oncol. 2022; 6: 001-003.

DOI: 10.29328/journal.jro.1001039

Copyright License: (c) 2022 Quintáns AT, et al. This is an open access article distributed under the Creative Commons Attribution License, which permits unrestricted use, distribution, and reproduction in any medium, provided the original work is properly cited.

Keywords: Tailgut cysts; Retrorectal hamartomas; Squamous cell carcinoma

\section{(4) Check for updates}

OPEn ACCESS

\section{Introduction}

Retrorectal cystic hamartomas (HCR) ("tailgut cyst" in English-language literature) are congenital cystic tumors derived from vestiges of the hindgut $[1,2]$. Their incidence is low, being more frequent in adult women. They are variable in size, uni or multiloculated [3]. They can be lined with several types of epithelium (squamous, transitional, mucinous,...) in the same cyst and can contain mucus. Lesions usually present during adulthood due to pain, discomfort, rectal bleeding, infection, or malignant transformation. The incidence of malignancy is low, being the adenocarcinoma and neuroendocrine tumor [4], the most frequent tumor type associated to HCR. We present a case of HCR associated with squamous cell carcinoma and discuss some aspects of its treatment.

\section{Case presentation}

69-year-old female patient who noticed, for more than a year, a tumor in the coccygeal region with progressive increase in size and painful in sitting position. Physical examination revealed a fluctuating soft subcutaneous tumor without inflammatory signs in the coccygeal region, measuring $3 \mathrm{~cm}$ approximately. Pelvic magnetic resonance imaging identified a bilobed lesion surrounding the second and third coccygeal bodies anteriorly and posteriorly, hyperintense in $\mathrm{T} 1$ and $\mathrm{T} 2$, cranially displacing the pelvic floor musculature, without supraelevator extension, measuring $29 \times 49 \times 50 \mathrm{~mm}$. The diagnosis was that of HCR through the entire posterior approach, with a free margin including the 3rd coccygeal body and preserving the elevator muscles and external sphincter (Figure 1).

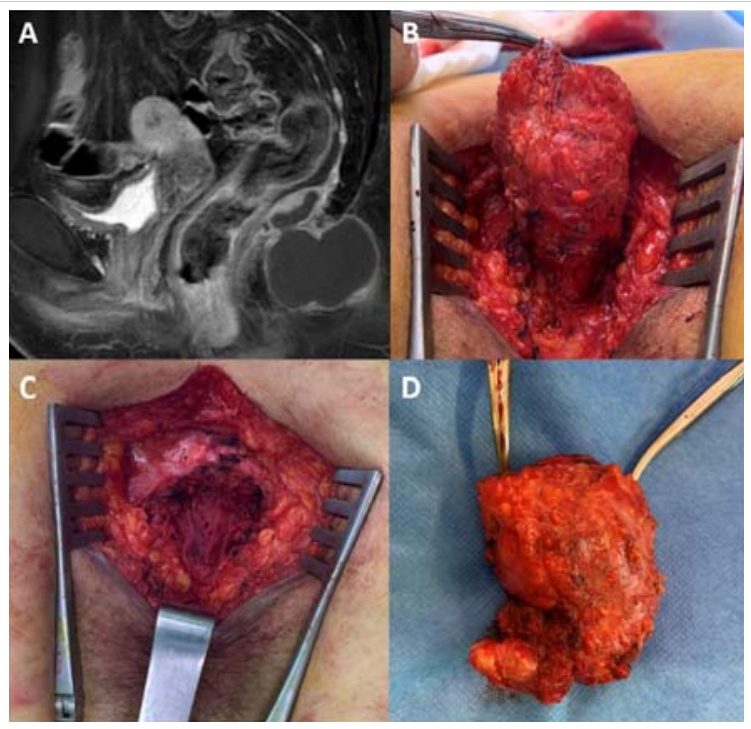

Figure 1: A: T1 Sagittal pelvis MRI image; B: Caudal view of surgical field. Elevator muscle in the background; C: Surgical field after tumor and coccyx resection ; D: Surgical specimen. It can be seen how the tumor involved the coccyx. 
The postoperative period was uneventful and the patient preserved absolute continence. The histological study confirmed the diagnosis of HCR lined by squamous epithelium with high grade dysplasia and the presence of moderately differentiated squamous cell carcinoma, with infiltration of the cyst wall and without reaching percystic fat. It presented a clear surgical margin of $2 \mathrm{~mm}$, with intratumoral perineural invasion and without lymphovascular invasion.

The proliferation index (Ki67) was 70\%, being tumor cells positive for p63, CK5-6 and p53 and negative for p16 (Figure 2). A PET-CT scan was performed not showing nodal or distant spread. We discussed the case in a multidisciplinary clinical session, deciding to perform adjuvant treatment with pelvic radiotherapy. The patient consulted to another Radiotherapy Service of other hospital who decided to treat only the surgical site with intensity-modulated radiation therapy (IMRT).

Although tailgut cysts are seen in all age groups, they are most common in middle-aged women [1]. They are generally asymptomatic and are diagnosed through localization in later ages. Symptoms associated with an enlarging mass include pain, rectal fullness, constipation, dysuria, obstructive and gynecological symptoms, as well as chronic abscess and fistula [5].

HCRs can be lined by various epithelia: squamous, transitional, mucinous, etc., and therefore malignant transformation from any of the cyst epithelial cell types could be possible. The incidence of malignancy is low, between 2 and $8 \%[4,6]$, although up to $40 \%$ has been described [7]. The largest published series is 53 patients with only 1 case with a malignant tumor [4]. The most common is adenocarcinoma and low-gradeneuroendocrine tumor, although endometrioid carcinoma to sarcomas have been described. We have only found two published cases of squamous cell carcinoma. In one case, the patient also received IMRT and 9 months later she presented tumor nodule next to the sciatic nerve (the authors do not provide further data) [8]. The other case was

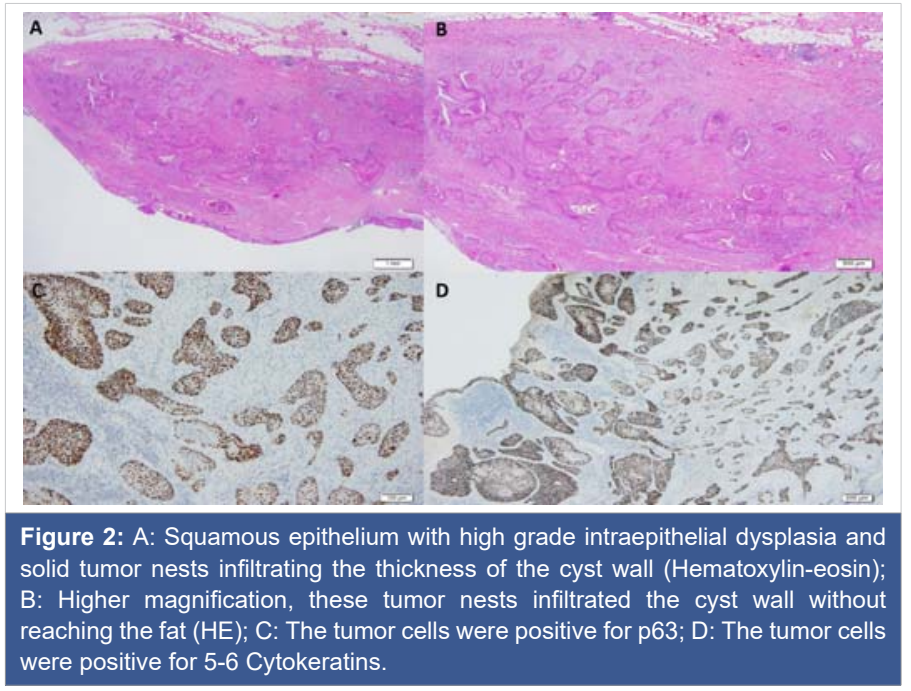

associated with synchronous rectal adenocarcinoma and received adjuvant chemotherapy with a FOLFOX-4 scheme after resection, being disease-free for 18 months [9].

The treatment of tailgut cysts is the dissection of the mass with clear surgical margins [6]. A surgical approach is supported for the anatomical site. The tumor committee discussed the type of treatment and the need for adjuvant treatment. Due to the lack of literature to support any decision, we assimilated the case to squamous cell carcinoma of the anal canal because the pathway of dissemination and biological behavior should be similar. There was unanimity on the limited benefit of use of adjuvant chemotherapy alone, as well as the possible benefit of radiotherapy in reducing the risk of locoregional recurrence. The type of radiotherapy that could provide the greatest benefit was discussed, and finally, based on the short distance to the margin, the very high proliferation index, the perineural invasion and the tumor phenotype, radiotherapy with IMRT including surgical site and locoregional lymph node chains was recommended. Radiotherapy limited to the surgical site may be as correct an adjuvant treatment as the one we have proposed. Resection of the coccyx is debated. Although some authors support it for a better exposure and less risk of recurrence [6], others consider its resection unnecessary [10]. Given the suspicion of malignancy, the existence of firm adherence to the coccyx or difficulty in bloc resection, it should be resected to avoid intraoperative rupture. Achieving an R0 bloc resection is important because most malignant tumors are incidental findings [4].

\section{References}

1. Krivokapic Z, Dimitrijevic I, Barisic G, Markovic V, Krstic M. Adenosquamous carcinoma arising within a retrorectal tailgut cyst: report of a case. World J Gastroenterol. 2005; 11: 6225-6227. PubMed: https://www.ncbi.nlm.nih.gov/pmc/articles/PMC4436647/

2. Tampi C, Lotwala V, Lakdawala M, Coelho K. Retrorectal cyst hamartoma (tailgut cyst) with malignant transformation. Gynecol Oncol. 2007; 105: 266-268.

PubMed: https://pubmed.ncbi.nlm.nih.gov/17303225/

3. Vega Menéndez D, Quintáns Rodriguez A, Hernández Granados $P$, Nevado Santos M, García Sabrido JL, et al. Tailgut cysts. Cir Esp. 2008; 83: 53-60.

4. Hjermstad BM, Helwig EB. Tailgut cysts. Report of 53 cases. Am J Clin Pathol. 1988; 89: 139-147.

PubMed: https://pubmed.ncbi.nlm.nih.gov/3277378/

5. Graadt van Roggen JF, Welvaart K, de Roos A, Offerhaus GJ, Hogendoorn PC. Adenocarcinoma arising within a tailgut cyst: clinicopathological description and follow up of an unusual case. J Clin Pathol. 1999; 52: 310-312.

PubMed: https://pubmed.ncbi.nIm.nih.gov/10474528/

6. Sakr A, Kim HS, Han YD, Cho MS, Hur H, etal. Single-center Experience of 24 cases of tailgut Cyst. Ann Coloproctol. 2019; 35: 268-274. PubMed: https://pubmed.ncbi.nlm.nih.gov/31726003/

7. Yang DM, Park CH, Jin W, Chang SK, Kim JE, et al. Tailgut cyst: MRI evaluation. Am J Roentgenol. 2005; 184: 1519-1523.

PubMed: https://pubmed.ncbi.nlm.nih.gov/15855109/ 
8. Demirel AH, Cetin E, Temiz A. Squamous cell carcinoma arising in a sacrococcygeal tailgut cyst. An Bras Dermatol. 2018; 93: 733-735. PubMed: https://pubmed.ncbi.nIm.nih.gov/30156628/

9. Gaud U. Goyal T, Shukla MM, Kumar V, Pandey M. Syncronous occurrence of adenocarcinoma of the rectum with squamous cell carcinoma of a retrorectal cyst: report of a case and review of the literatura. BMJ Caser Rep. 2009; 2009: bcr12.2008.1398. PubMed: https://pubmed.ncbi.nlm.nih.gov/21686338/

10. Böhm B, Milsom JW, Fazio VW, Lavery IC, Church JM, et al. Our approach to the management of congenital presacral tumors in adults. Int J Colorectal Ddis. 1993; 8: 134-138.

PubMed: https://pubmed.ncbi.nlm.nih.gov/8245668/ 